\title{
Juventudes contemporâneas, cotidiano e inquietações de pesquisadores em Educação - uma entrevista com José Machado Pais
}

\section{Contemporary youths, daily life and restlessness of researchers in Education - an interview with José Machado Pais}

\author{
José Machado Pais ${ }^{1}$ \\ Miriam Pires Corrêa de Lacerda ${ }^{2}$ \\ Victor Hugo Nedel Oliveira ${ }^{2}$
}

\begin{abstract}
RESUMO
José Machado Pais é professor do Instituto de Ciências Sociais (ICS) da Universidade de Lisboa (ULisboa). O Dr. Pais tem se dedicado ao ensino e tutoria de estudantes de Doutorado e é Professor Convidado do ISCTE/ Instituto Universitário de Lisboa. Foi Professor Visitante em várias universidades europeias e sul-americanas. Tem dirigido projetos internacionais europeus em vários domínios das Ciências Sociais. Coordenou o Observatório Permanente da Juventude Portuguesa e o Observatório das Atividades Culturais. Nesta entrevista, concedida aos professores Miriam e Victor, o professor Pais discute temas importantes para o campo de pesquisa na área de juventudes, bem como apresenta pistas para as opções metodológicas no campo do registro do cotidiano. Ele afirma que o olhar pode ser um bom instrumento para a decifração dos códigos vividos no cotidiano, onde “tudo passa sem que nada pareça passar". José Machado Pais destaca que os processos de transição da juventude para a vida adulta continuam marcados
\end{abstract}

DOI: $10.1590 / 0104-4060.50119$

1 Universidade de Lisboa. Lisboa, Portugal. Avenida Prof. Aníbal Bettencourt, nº 9, 1600189. E-mail: machado.pais@ics.ulisboa.pt

2 Pontifícia Universidade Católica do Rio Grande do Sul. Porto Alegre, Rio Grande do Sul, Brasil. Av. Ipiranga, nº668. Partenon. CEP: 90619-900.E-mails: miriam.lacerda@pucrs.br e victor.nedel@acad.pucrs.br 
pela imprevisibilidade. Enfatiza a necessidade de explorar o cotidiano como um campo de produção imaginária, de criatividade.

Palavras-chave: juventudes; Sociologia do Cotidiano; Educação.

\begin{abstract}
José Machado Pais is a professor at the Institute of Social Sciences (ICS) of the University of Lisbon (ULisboa). Dr. Pais has been dedicated to the teaching and mentoring of doctoral students and he is a Visiting Professor at ISCTE / Lisbon University Institute. He was a Visiting Professor at several European and South American universities. He has led international European projects in various fields of Social Sciences. He coordinated the Permanent Observatory of Portuguese Youth and the Observatory of Cultural Activities. In this interview, granted to the teachers Miriam and Victor, Professor Pais discusses important issues to the research field in the youth area and he offers clues to the methodological options in the daily life record field. He says that the look can be a good tool for deciphering the code experienced in everyday life, where "everything goes on without feeling anything going on." José Machado Pais points out that the youth transitions to adulthood are still marked by unpredictability. He emphasizes the need to explore everyday life as an imaginary field of production, creativity.
\end{abstract}

Keywords: youths; Sociology of Everyday Life; Education.

\title{
Apresentação
}

José Machado Pais é um dos mais importantes pesquisadores das Juventudes na atualidade. Desde o início de seu interesse pela pesquisa no campo das Juventudes, no final dos anos 1980, já publicou uma série de importantes obras que se tornaram referências mundiais para os estudiosos do campo.

No segundo semestre de 2016, no Programa de Pós-Graduação em Educação da Pontifícia Universidade Católica do Rio Grande do Sul, foi oferecida a disciplina denominada "Sociologia da Educação: Cotidianos e Juventudes", sob a regência da Professora $\mathrm{Dr}^{\mathrm{a}}$. Miriam Pires Corrêa de Lacerda, líder do Grupo de Estudos sobre as Juventudes Brasileiras, que compõe a Linha de Pesquisa "Formação, Políticas e Práticas em Educação". Essa disciplina destacou a importância dos conhecimentos cotidianos para uma compreensão dos tempos e dos múltiplos espaços pelos quais transitam as Juventudes. A principal obra 
estudada nessa disciplina foi "Vida Cotidiana: Enigmas e Revelações", de autoria do Professor Doutor José Machado Pais.

Nesta entrevista, realizada em Lisboa, aos três dias do mês de outubro do ano 2016, são apresentadas sínteses analíticas desenvolvidas pelo Professor José Machado Pais, decorrentes de sua ampla pesquisa e experiência no campo das juventudes e da sociologia do cotidiano.

Entrevistadores: A partir de seus estudos na área das Juventudes, o que o senhor pensa da dissociação entre o mundo da escola e o mundo da vida?

José Machado Pais: Essa foi uma interrogação que a mim próprio me coloquei quando comecei a minha carreira de professor. Dava então aulas de matemática no ensino secundário. Quando apanhava alguns alunos aparentemente distraídos, sussurrando entre si, sempre me questionava: De que estarão falando? Da incógnita da equação ou do que fizeram ou vão fazer depois da aula? Minha reação era parar de falar até que eles próprios parassem de cochichar. Então desafiava-os a partilhar o que estavam cochichando. Nada que a ver com a matéria debitada... Como interpretar tamanha dissonância de interesses? O que vai na cabeça de um aluno quando um professor está debitando matéria? Em que se concentra quando está distraído? O que favorece ou impede a partilha de ideias numa sala de aula? Como são tecidas as relações cotidianas entre professores e alunos? Como se refletem essas relações nos processos de aprendizagem? Tomando por referência as matérias tidas como mais abstratas ou difíceis, como é o caso da matemática, pode questionar-se que utilidade tem para o mundo da vida o que se aprende no mundo da escola. O mesmo em relação à música, à poesia, ou à química.... Pergunto, deve a escolarização guiar-se por um padrão meramente utilitarista? Duvido. Em contrapartida, há que mostrar aos alunos a importância que tais matérias podem ter na formação humana e no alargamento dos horizontes de conhecimento. De um conhecimento que será tanto mais apetecível quanto mais interesse despertar. No caso da Matemática, por exemplo, não é passando exercícios para se realizarem como um castigo que se desperta o interesse de aprendizagem. Há que mostrar a beleza da matemática nas suas relações com a filosofia; a sua ludicidade quando, por exemplo, se projeta na composição musical; a sua instrumentalidade quando é chamada a resolver problemas concretos do dia a dia ou a antecipar soluções que facilitem a vida. É o conhecimento prático, do mundo da vida, que permite que o mesmo avance quando se olha ao espelho do que vai produzindo. Por outro lado, a escola tem de estar preparada para acolher uma população estudantil crescentemente heterogénea, sem que a inclusão social promovida pelo acesso ao ensino tenha de ser colocada em antinomia com a qualidade do mesmo. Lamentavelmente, um dos efeitos perversos da massificação do ensino tem sido a febre da corrida 
aos títulos, pouco contando o modo como se obtêm. A titulomania nem sempre favorece o gosto pela aquisição de conhecimentos. A satisfação intrínseca pela aprendizagem, dando vida ao mundo da escola, é também a melhor forma de fazer do mundo da vida uma escola.

E que dizer da tão propagada dissociação entre o mundo da escola e o do trabalho? Para muitos jovens europeus, onde o desemprego juvenil é acentuado, nem o sistema educativo nem o mercado de trabalho parecem capazes de garantir a realização das suas aspirações profissionais. No entanto, muitas teses equívocas têm sido construídas a propósito do desemprego juvenil. Nas últimas décadas do século passado, uma boa parte dessas teses invocava uma alergia dos jovens ao trabalho. Outras, mais recentes, insistem na desadequação do sistema de ensino ao mercado de trabalho. A realidade mostra que essas teses são frequentemente falaciosas. Nos países europeus mais atingidos pelo desemprego juvenil (Espanha, Grécia, Portugal e Itália) - onde essas teses mais circulam - o desemprego atingiu recentemente níveis elevadíssimos. Alergia ao trabalho? Não parece ser o caso. Muitos jovens buscam desesperadamente trabalho e não o encontram. Será que a culpa é do sistema de ensino, porque não consegue adequar-se ao mercado de trabalho? Ou será que o problema está em estruturas produtivas arcaicas que sobrevivem à custa de mão de obra barata? Eu creio que essa hipótese deveria ser mais seriamente considerada. Por que razão é que muitos jovens desempregados não conseguem arranjar emprego nos seus países, apesar de suas elevadas qualificações, incluindo doutoramentos em áreas científicas de vanguarda? Provavelmente porque nos seus países de origem as estruturas produtivas arcaicas não têm capacidade de integrá-los profissionalmente. Em contrapartida, quando emigram para países economicamente mais desenvolvidos, ou em franco desenvolvimento, esses mesmos jovens arranjam facilmente emprego. Não podemos menosprezar as condições sociais que criam ou bloqueiam as estruturas de oportunidade para a criação de emprego e sobre as quais as políticas públicas não podem deixar de atuar.

\section{Entrevistadores: Em 2001, o senhor escreve "Ganchos, Tachos e Bis-} cates", obra na qual o senhor defende uma sociologia na não-linearidade para explorar tanto o universo do trabalho quanto das socialidades juvenis. Que mudanças, desde então, o senhor percebe nesse campo?

José Machado Pais: Eu diria que os processos de transição para a vida adulta, embora se tenham complexificado, continuam a ser marcados pela imprevisibilidade. Daí a recorrência de conceitos como os de giro biográfico, encruzilhadas de vida, turning points, etc. Em seu livro Assim Falava Zaratustra, Nietzsche sugeria que a vida se encontra balizada por dois únicos pontos fixos, o nascimento e a morte. Entre esses dois pontos há um meio, uma travessia, 
como diria Guimarães Rosa, um mistério, um mundo de constrangimentos e possibilidades. É no meio desse meio que temos um vasto campo de problematizações sociológicas. Meu guia metodológico, tomo-o de um repentista brasileiro que dizia: "eu só comparo esta vida às curvas que da letra $\mathrm{S}$, tem uma ponta que sobe, tem outra ponta que desce... As curvas que dá no meio nem todo o mundo as conhece"... Cá temos o misterioso meio, o desconhecido, a imprevisibilidade das curvas e contracurvas de vida que aparecem associadas a tropeços, a itinerários ziguezagueantes, a rumos indefinidos. Esses trânsitos de vida são incompreensíveis sem um conhecimento objetivo das regras desses trânsitos, dos seus ordenamentos sociais e institucionais, da semântica coletiva da vida social - constituída por crenças, valores, cultura. Aqui, sim, registaram-se mudanças significativas. Para além da globalização e da crescente tecnologização dos meios de produção e comunicação, no campo económico ou cultural, nas novas correntes socioculturais os valores cada vez mais ambivalentes, perderam rigidez, brigam entre si num campo propenso ao relativismo. O que constatamos, na base de vários inquéritos aos jovens, é que eles abraçam valores aparentemente antagónicos: materialistas e pós-materialistas; hedonistas e espiritualistas; individualistas e sociocêntricos. Para os jovens de hoje os direitos sociais mais atrativos são os que se expressam no bem-estar individual, como os que se centram em questões relacionadas com o género, a sexualidade, os estilos de vida, a qualidade da mesma. Daí que a teoria das ações coletivas venha dando um crescente acolhimento aos chamados lifestyles movements, ancorados à cidadania da intimidade.

Recentemente, tem sido dada uma crescente atenção às escolhas biográficas dos jovens, aos processos de individuação e subjetivação... Em boa hora. Por aí devemos continuar. No entanto, na análise dos processos de transição para a vida adulta não podemos deixar de entrecruzar escolhas biográficas e estruturas sociais. As estruturas sociais são o tabuleiro onde se jogam as trajetórias de vida e as escolhas biográficas. Embora a fuga aos destinos prováveis seja hoje em dia mais plausível do que há algumas décadas , a condição social dos jovens, sua pertença de classe, continuam a pesar na eleição e concretização das suas escolhas biográficas. É como no futebol. Quando começa um jogo, teoricamente qualquer dos times tem possibilidade de ganhar. Mas na prática não é bem assim. As equipas melhor apetrechadas e preparadas têm mais chances de vencer.

O jogo da vida não é, contudo, um jogo de xadrez ou de futebol. Em qualquer jogo há dois tipos de conhecimento: o das regras do jogo e o do jogo praticado. As regras são determinadas por quem as inventou; em contrapartida, na prática do jogo criam-se estratégias que o jogador vai adotando para alcançar sucesso. Isto é o que se passa num tabuleiro de xadrez ou num campo de futebol. O palco da vida é mais complicado, pois assemelha-se a uma estrutura labiríntica. 
Há dois tipos de estruturas labirínticas: as fixas e as móveis. Nas fixas, como no labirinto de Creta da mitologia grega, há uma divergência de conhecimento entre o arquiteto e o viajante, entre Dédalo e Teseu. Para o arquiteto o labirinto tem uma estrutura lógica; para o viajante é um mistério interpretativo. Mais complexas são as estruturas labirínticas de natureza social. Por quê? Porque elas são móveis. Mudam as estruturas e os caminhantes ajudam a mudá-las. É nesse cenário que decorrem as trajetórias juvenis. O que, entretanto, mudou? A crescente capacidade que os jovens têm de atuar como protagonistas de novos rumos societais e de novas correntes socioculturais... Por quê? Porque no confronto intergeracional os jovens de agora fazem parte de uma geração incomparavelmente mais escolarizada, isto apesar de ainda persistirem fortes desigualdades no acesso ao sistema de ensino.

\section{Entrevistadores: Que rumos o senhor acredita que tomará a pesquisa no campo das juventudes, em tempos nos quais as juventudes se tornaram o ideal da cultura?}

José Machado Pais: Na sua pergunta levanta-se uma hipótese de correlação entre tempos e rumos. Provavelmente teremos de levar mais a sério as inspiradoras reflexões de Frederic Jameson, a propósito dos prováveis rumos societais nos tempos que correm. No seu livro Postmodernism, or the Cultural Logic of Late Capitalism, o que o Jameson nos sugere é uma crescente espacialização da experiência, porque essa tende a desvincular-se do tempo; daí decorre o conceito de atemporalização, como se o tempo fosse engolido pelo espaço. Daí o eclipse da linearidade temporal, a emergência de um tempo fragmentado, descontínuo, caótico, disperso. Na medida em que o tempo se esvai, dá-se uma redução da experiência ao aqui e agora. Que implicações sociais pode ter essa presentificação, tão presente nas culturas juvenis contemporâneas? Possivelmente a perda de vista dos horizontes do futuro e das memórias sociais do passado. Essa é uma, entre muitas outras temáticas, que merece ser aprofundada. O futuro já não se planeia a longo prazo, as decisões adoptam-se e adaptam-se em função de circunstâncias mutáveis. Já não se anda atrás do futuro, corre-se atrás de pókemones. São muito mais fáceis de agarrar do que o futuro. E curiosamente são os jovens, de quem se diz que são o futuro, que andam mais atrás de pókemones, deixando para o lado o futuro. Isso deve ter um significado e uma explicação. Como quer que seja, não creio que essa presentificação seja necessariamente patológica, como o sugere Harmut Rosa em seu livro Social Acceleration: a New Theory of Modernity. A presentificação pode ser um tempo de conquista quando se exploram brechas no futuro indeterminado. 
Entrevistadores: Em "Sociologia do Cotidiano" o senhor apresenta o pesquisador-viajante-flâneur como metáfora para dizer daquele que precisa se perder para poder se encontrar. Entendemos que o registro dessas práticas podem se dar pela via da cartografia. $O$ senhor poderia explorar mais essa ideia?

José Machado Pais: Uma vez, José de Souza Martins, ele que também pesquisa nos trilhos do cotidiano, avançou, gracejando, uma curiosa e bem ampla definição de um tão escorregadio objeto de pesquisa: "cotidiano é isso aí..." - ao mesmo tempo que estendia o beiço inferior para a imensidão do isso aí.... Ou seja, o cotidiano não é um objeto de estudo empiricamente delimitável, ao contrário de outros domínios do saber. O cotidiano é antes uma possibilidade metodológica de decifração do social. Daí o apelo a deambularmos pela imensidão do isso aí. Os riscos (ou ganhos) de nos perdermos podem ser compensados (ou potenciados) convocando um olhar seletivo e sensibilizado, desde logo do ponto de vista teórico. Com uma dupla preocupação: a ver a sociedade a nível dos indivíduos e, ao mesmo tempo, a de ver como o social se traduz na vida deles. É com esse guia de orientação metodológica que podemos cartografar o social, com o objetivo de o melhor o interpretar. Ray Birdwhistell, antropólogo da Universidade de Chicago, mobilizava os seus alunos para essas descobertas naturalísticas. Por exemplo, pedia-lhes que identificassem o status social dos transeuntes a partir da observação do calçado que usavam. Ao que parece confiava mais nesse método de observação naturalística do que na famosa escala que o seu professor William Warner usava para analisar a estratificação social - escala que ainda hoje é usada nas surveys por sondagem. Entre os alunos de Birdwhistell encontrava-se Goffman que, seguindo as peugadas de seu mestre, viria a desenvolver uma brilhante sociologia das interações cotidianas.

Entrevistadores: Através da leitura de muitos de seus trabalhos, somos apresentados a ricas metáforas. Como o senhor articula a vida cotidiana "onde tudo passa sem que nada pareça passar" com a produção intelectual?

José Machado Pais: Como nos ensinou Clifford Geertz (Local Knowledge) a compreensão de uma cultura assemelha-se mais a entender um provérbio, a captar uma ilusão ou a perceber uma piada do que a alcançar uma idealizada totalidade. Por isso em minhas pesquisas valorizo provérbios, piadas, grafitis, apelidos, letras de música, mensagens de pacotes de açúcar, adesivos escarrapachados nas traseiras de carros, etc. $\mathrm{O}$ que busco são sempre excedentes de significação no aparentemente insignificante. Daí a minha proposta de uma metodologia de questionamento do social que toma como relevante o aparentemente irrelevante. Vou na peugada de Sherlock Holmes quando reconhecia que em suas pesquisas buscava sempre o inesperado, numa lógica de descoberta, ao 
contrário daqueles que só questionam o que pressupõem. Entretanto, voltando à sua pergunta anterior, gostaria de referir que cartografar o social, nas suas minudências cotidianas, é um desafio tanto mais estimulante quanto mais nos damos conta de que os enigmas do presente não podem ser decifrados sem convocar a sua historicidade. $\mathrm{O}$ que estou a sugerir é que cartografia do cotidiano tem de ser dinâmica, contemplar a temporalidade. Não basta ser fotográfica, tem de ser fílmica. Só desse modo conseguiremos desenvencilhar o cotidiano de sinónimos que o amarram à banalidade, à monotonia, à repetitividade. Há que explorar o cotidiano como um campo de produção imaginária, de criatividade. A vida cotidiana não é um mero cenário de reprodução social, embora a alienação surja frequentemente como uma sombra do cotidiano, na linha das propostas de Henri Lefebvre. No entanto, ao contrário de Lefebvre, eu proporia uma distinção entre cotidiano e cotidianidade. Na cotidianidade teríamos a rotina, no cotidiano teríamos também o que quebra a rotina, isto é, a rotura. O que com isso quero dizer é que a vida cotidiana é também um campo de resistências e lutas sociais.

Entrevistadores: Para além das narrativas, que outras formas de registro seriam interessantes para cartografar o cotidiano?

José Machado Pais: Podemos cartografar o cotidiano através do olhar, por exemplo. Como bem referiu Simmel, num pequeno ensaio sobre a sociologia do sentido (Sociologie et Épistémologie), o olhar é um recurso notável da observação sociológica. Aliás, já Balzac, na sua Comédia Humana, reivindicava, sem rodeios, uma gastronomia do olhar como ciência de apreensão das cidades. A vida cotidiana é um terreno onde se vive a experiência antropológica do olhar, de uma vadiagem do olhar que, só com sensibilidade teórica, consegue captar o que se oculta no que é visível. Por isso mesmo as imagens não devem ser consideradas um espelho do real, como supostamente se pensa acontecer com a fotografia, tantas vezes ingenuamente olhada como uma técnica de congelamento do real, assim se legitimando o seu uso equívoco como fotocópia do social. As imagens valem por si enquanto realidade sociológica. Elas representam sempre realidades excedidas que se exacerbam no modo como e por quem são representadas. Frequentemente ofereço máquinas fotográficas descartáveis a quem, através do seu olhar, me dá ensejo de ver a forma como o mundo pode ser visto e representado. Desse modo posso captar o mundo através dos olhar de quem o vê. As fotografias ajudam-nos a encenar realidades que escapam à categorização verbal da comunicação através da entrevista. Na própria entrevista deveríamos valorizar o registo do silêncio. A escuta do silêncio coloca-nos o desafio de o saber interpretar. Hoje temos sofisticados pacotes de software de apoio à análise qualitativa. Porém, esbarram num impasse quando são chamados a interpretar o silêncio. São incapazes de descobrir o significado que soa no silêncio de qual- 
quer palavra. Da mesma forma que o dizer não apenas desvenda como oculta, o silêncio também revela no que aparentemente encobre. O poeta Manoel de Barros, em seus Ensaios Fotográficos, sugere que é difícil fotografar o silêncio. Mas não deixou de o tentar. Também temos de saber interpretar o silêncio. Para tanto temos que desenvolver uma arte de escuta, como nos propôs Erich Fromm. Sem escuta a palavra não tem existência. Nem o silêncio. Nem o pensamento. Nem o diálogo. Nem a compreensão do que nos rodeia. Na análise de conteúdo das entrevistas nem sempre é dada relevância ao silêncio. A escuta atenta do silêncio transforma-se numa possibilidade de abertura ao outro, num exercício de alteridade que nos coloca em melhor posição para interpretar os registos de observação. Na escuta temos uma fascinante possibilidade de diálogo, como tive a oportunidade de constatar numa pesquisa que realizei sobre a solidão (Nos Rastos da Solidão. Deambulações Sociológicas).

Entrevistadores: Com o incremento dos processos migratórios forçados no século XXI, principalmente de jovens da América Central, do norte da África e do oriente médio, para destinos com supostas melhores oportunidades, como o senhor pensa que se dão as novas conexões e os novos pertencimentos aos espaços?

José Machado Pais: Os fluxos de migração na viragem do último século inscrevem-se numa economia de desejos e imaginários, onde as realidades locais incentivam a busca de oportunidades globais. É em contextos de contingência que se delineiam estratégias de sobrevivência, muito orientadas pela circulação, o trajeto como parte constituinte do projeto de vida. As novas tecnologias de informação e comunicação têm tido um papel relevante no alargamento dos horizontes desses desejos e imaginários. O que acontece é que alguns dos jovens encontram-se encalacrados entre futuros herdados, onde pesa a tradição e a pobreza, e futuros desejados nem sempre de fácil concretização. Os primeiros encontram-se estruturalmente enraizados; os segundos são guiados por experiências reflexivas, socialmente partilhadas, em cenários de incerteza que, apesar de tudo, não deixam de alimentar a esperança. Escapar aos futuros herdados, que já não são futuro, acalenta os sonhos de emigração. Porém, chegados aos países de destino, os futuros desejados transformam-se frequentemente num pesadelo, dadas as dificuldades de integração nas sociedades de destino. Os imigrantes são muitas vezes olhados como uma ameaça aos países de acolhimento: por pressionarem o mercado de trabalho, por serem portadores de uma cultura diferente, pelos níveis de pobreza entre muitos deles. São bem conhecidos os fenómenos de segregação urbanística que culminam numa ocupação socialmente diferenciada do espaço urbano: as elites refugiam-se em condomínios fechados, resguardados por gradeamentos, muros, arame farpado ou câmaras 
de vigilância. As camadas populares, com sobre-representação dos imigrantes, são empurradas para periferias degradadas onde bandos de jovens vagueiam à margem do mercado de trabalho e sem aspirações de futuro. $\mathrm{O}$ espectro da fractura social não é uma ameaça, é uma realidade. O desafio da convivência democrática passa por eficazes estratégias de integração social, pois só assim a diversidade cultural se constitui num potencial criativo, ou seja, num factor de enriquecimento recíproco.

Entrevistadores: Temos juventudes que, a seu modo, ocupam territórios urbanos. Como o senhor percebe que se dá a apropriação do espaço urbano a partir de diferentes recortes socioeconômicos-culturais?

José Machado Pais: Há que distinguir diferentes tipos de apropriação. Por exemplo, há apropriações de marcado de cunho hedonista. Aparecem associadas a sociabilidades inscritas em circuitos de lazer noturno. A sacralização da celebração grupal é frequentemente assegurada por consumos (bebidas e drogas) e fachadas corporais (tatuagens, piercings, várias indumentárias), fenómenos que dão razão a Peter Burke quando nos sugere a necessidade de uma teoria política da moda para melhor percebermos a natureza dos conflitos sociais, já que as identidades sociais aparecem estreitamente vinculadas a políticas de submissão ou de resistência e rebeldia. Nesse último caso surgem apropriações criativas que envolvem jovens grafiteiros, skaters, músicos de rua e outros artistas. Há apropriações cívico-políticas que transformam o espaço público num palco de protestos, manifestações, reivindicações políticas, mas há também apropriações que são a face oculta de uma expropriação: o direito à dignidade. É o caso de jovens sem teto e de alguns jovens dos subúrbios sem esperança no futuro. Nesses territórios de marginalidade social é frequente dar-se uma integração perversa, reforçada por etiquetas que diabolizam os seus destinatários. Essa integração de margem é um claro exemplo de communitas, no sentido que Turner lhe dava, ao enfatizar vínculos sociais que se produzem em condições de liminaridade, de indeterminação, de carência de expectativas em relação ao futuro. Dado que resulta difícil, para jovens vivendo em situações de marginalidade, afirmarem a sua diferença identitária nas tramas da sociedade convencional - ou da marginalidade saírem quando a diferença é uma clara manifestação de exclusão social - alguns deles investem em redes relacionais de proximidade de bairro ou de rua, de acordo com o princípio qui se ressemble s'assemble. Ou seja, assiste-se a uma fragmentação urbana que leva à coexistência de várias cidades na mesma cidade. Em causa uma estrutura de desigualdade de oportunidades no que diz respeito ao acesso de bens materiais e simbólicos que a cidade tem, ou não, para oferecer. 


\section{Entrevistadores: Quais as recomendações o senhor considera essen- ciais entrarem na agenda dos "jovens pesquisadores de juventudes"?}

José Machado Pais: Para além de rigor metodológico, em obediência a princípios éticos, requerem-se conceitos inovadores e críticos. No léxico das ciências sociais há conceitos que, desgastados pelo tempo, perderam a eficácia heurística que tinham. No seu poema menino do mato, Manoel de Barros descobre o verme desses conceitos quando sustenta que há palavras bichadas de costume. Muitos conceitos usados nos estudos da juventude como os de subcultura, tribos, ciclo de vida, trabalho, jovens nem-nem, etc. exigem cuidada vigilância epistemológica. Alguns conceitos deixam escapar as relações de reciprocidade entre polos opostos de aparentes contradições: o objetivo e o subjetivo, o micro e o macro social, o acontecimento e o histórico, etc. As experiências cotidianas constituem uma fonte de aprendizagem do mundo da vida. Por isso, devemos explorar as minudências da vida social, as potencialidades interpretativas de aspetos aparentemente anódinos da vida cotidiana que nos podem dar pistas sobre as dinâmicas e processos sociais. Por exemplo, as sociabilidades juvenis, as imagens corporais, a linguagem nativa dos jovens, as suas gírias, o seu calão. Nessa perspectiva há que valorizar os achados de terreno, estimular a grounded theory, explorar os conceitos sensibilizantes que nos chegam nas linguagens nativas, como nos propõe Blumer. Há que ver como os nomes rodopiam sentidos no linguarejar da vida cotidiana. Mas como chegar a esses sentidos? Explorando as razões mundanas que fundamentam a criatividade linguística entre os jovens, na linha das propostas de Melvin Pollner. Recentemente tenho pesquisado a simbologia dos apelidos na vida cotidiana escolar, tanto em Portugal como no Brasil. Ao apelidarem os colegas, os professores e os funcionários da escola, os jovens fazem da escola um espaço recriado, cotidianamente reinventado, onde se estimula uma produção comunicativa dissidente, em que a sintaxe se corrompe num jogo que integra dimensões do ser, do parecer e do prazer.

Atenção também tem de ser dada ao uso que os jovens fazem das novas tecnologias de informação e comunicação. Em seu livro Networks of Outrage and Hope. Social Movements in the Internet Age, Castells questiona-se sobre as razões que detonaram os movimentos sociais juvenis por todo o mundo, nos inícios do presente século. As redes sociais tiveram um papel determinante na mobilização dos jovens. Eles interconectam-se, tecem tramas de cumplicidade, envolvem-se em novas formas de comunicação de suporte à participação cívica e política: websites, facebook, blogs, fóruns, protestos online, etc. Muitos questionam os interesses mercantis associados ao controlo da informação digital, reivindicando a sua partilha como um direito universal. Por isso defendem formas alternativas de consumo e distribuição da cultura, como é o caso dos conteúdos até agora protegidos pelas leis de direitos de autor e da propriedade intelectual: 
filmes, músicas, livros, vídeos, etc. Ou seja, as redes sociais permitem aos jovens novas formas de participação cívica e protagonismo político que tomam lugar num terreno manifestamente cultural. É evidente que o acesso às redes sociais não se encontra democratizado e, dependendo do uso, as redes sociais também podem favorecer condutas alienantes. Mas é importante pesquisar novas janelas de oportunidade, de participação e de emancipação que se abrem neste domínio relacional dominado pelas novas tecnologias.

Por outro lado, temos de ver como, entre os jovens, se jogam os naipes do tempo, isto é, as percepções do presente, as memórias do passado e as expectativas do futuro. As memórias do passado e a confiança - ou, no mínimo, a esperança - no futuro dão sentido aos tempos de transição da vida: da vida individual e da vida social. Temos de saber analisar como as sombras do passado se projetam no presente, sejam elas uma ameaça ou um estímulo. Temos também de ver a (in)capacidade do presente em gerar o futuro como possibilidade antecipada. É importante que os estudos da juventude possam ser apoiados e disseminados, inspirando políticas criativas que tomem os jovens como agentes de inovação e mudança social, políticas que não se limitem a ficar amarradas ao que se projeta fazer e não é feito. Refiro-me a políticas económicas e culturais que, articuladas às ciências, às artes e às tecnologias, se orientem por desafios à criatividade e que, se bem-sucedidas, acabarão por impulsionar novos rumos societais e novos horizontes profissionais. As pesquisas até agora realizadas têm mostrado que os jovens poderão ter um papel determinante como potenciais agentes de mudança social.

\section{Publicações do Autor (seleção)}

PAIS, J. M. Culturas Juvenis. Lisboa: Imprensa Nacional-Casa da Moeda, 1993.

PAIS, J. M. Traços e Riscos de Vida. Uma Aproximação Qualitativa a Modos de Vida Juvenis. Porto: Ambar, 1999.

PAIS, J. M. Ganchos, Tachos e Biscates. Jovens, Trabalho e Futuro. Porto: Ambar, 2001.

PAIS, J. M. Sociologia da Vida Quotidiana. Teorias, Métodos e Estudos de Caso. Lisboa: Imprensa de Ciências Sociais, 2002.

PAIS, J. M. Vida Cotidiana: Enigmas e Revelações. São Paulo: Cortez, 2003.

PAIS, J. M. Tribos Urbanas. São Paulo: Annablume, 2004. 
PAIS, J. M. Tribos Urbanas. Produção Artística e Identidades. Lisboa: Imprensa de Ciências Sociais, 2004.

PAIS, J. M. Nos Rastos da Solidão. Deambulações Sociológicas. Porto: Âmbar, 2006.

PAIS, J. M. Lufa-Lufa Quotidiana: Ensaios sobre Cidade, Cultura e Vida Urbana. Lisboa: Imprensa de Ciências Sociais, 2010.

PAIS, J. M. Sexualidades e afectos juvenis. Lisboa: Imprensa de Ciências Sociais, 2012.

Texto recebido em 02 de janeiro de 2017. Texto aprovado em 10 de janeiro de 2017. 
